\title{
Sexual behavior and reproductive health among HIV infected adolescents in RBC, IHDPC, Clinic during 2011 therapeutic holidays
}

Ange Anitha Irakoze*, Diane Tuyishimire, B Ami Bugingo, Sabin Nsanzimana, M Josee Maliboli, Melanie Muhizi, Angelique Nkuliza, Simon Niyonsenga, M Gasana, Ciprien Baribwira, Jackson Sebeza, Laetitia Umulisa

From 17th International Symposium on HIV and Emerging Infectious Diseases (ISHEID) Marseille, France. 23-25 May 2012

\section{Background}

Access to SRH services for adolescents in general and for HIV infected specifically is still challenging, resulting in low level of awareness, unsafe sex practices, risk of pregnancies, STI , contamination or super infection.

\section{Objectives}

To determine the patterns of sexual behavior, reproductive health among HIV infected adolescents followed at IHDPC/RBC HIV clinic.

\section{Methods}

During 2011 therapeutic holidays for HIV adolescents followed in RBC/IHDPC/HIV Clinic, 151 of them (73 girls and 78 boys) were assessed about sexual behavior and SRH using a modified HEEADS assessment self-administrated questionnaire and interviews. Parental permission was sought.

\section{Results}

The mean ages (+/-SD) of the girls and boys were $16.3+/-$ 0.165 years.

About disclosure: $8.7 \%$ of the adolescents were not willing to disclose their HIV status to their sexual partners, yet $76 \%$ of interviewed have a partner.

About safe sex: Overall, 8.4\% of adolescent are sexually active all above $15 y$ ears ( $4.4 \%$ of the girls and $12 \%$ of the boys). Boys are three times more sexually active than girls and $66.7 .1 \%$ of sexually experienced boys had used condoms. Among sexually experienced girls only
$33.7 \%$ used condoms, surprisingly $96.6 \%$ of interviewed declared not willing to have protected sex.

About Contraception and pregnancy: among sexually experienced girls $36.7 \%$, had ever used contraception and prevalence of adolescent pregnancy was $2.6 \%$.

Information about sexuality: $81.12 \%$ of adolescents have ever learnt about sexuality (51.7 \% aged 15-19 years), $49.6 \%$ can discuss sexual issues, among them $55 \%$ are girls and $45 \%$; are boys.

\section{Conclusion}

In this adolescent cohort, sexual activity seems to debut after 15 years old, safe sex practice is not optimal, and contraception among sexual actives girls is low and information level about SRH need to be improved, underling the urgent need of implementing SRH program for HIV adolescents.

Published: 25 May 2012

doi:10.1186/1742-4690-9-S1-P102

Cite this article as: Irakoze et al:: Sexual behavior and reproductive health among HIV infected adolescents in RBC, IHDPC, Clinic during 2011 therapeutic holidays. Retrovirology 2012 9(Suppl 1):P102.

\footnotetext{
* Correspondence: irakozeange@gmail.com

Rbc, Ihdpc, Hiv Division.Former Trac Plus, Kigali, Rwanda
}

(c) 2012 Irakoze et al; licensee BioMed Central Ltd. This is an Open Access article distributed under the terms of the Creative Commons Attribution License (http://creativecommons.org/licenses/by/2.0), which permits unrestricted use, distribution, and reproduction in any medium, provided the original work is properly cited. 